УдК 330.341

DOI 10.18101/2304-4446-2019-2-82-90

\title{
РАЗВИТИЕ МЕТОДИКИ ОЦЕНКИ КОГНИТИВНОГО ПОТЕНЦИАЛА РЕГИОНАЛЬНОЙ ЭКОНОМИКИ
}

\author{
(C) Цыренов Даши Дашанимаевич \\ кандидат экономических наук, \\ Бурятский государственный университет имени Доржи Банзарова \\ Россия, 670000, г. Улан-Удэ, ул. Смолина, 24а \\ E-mail: dashi555@mail.ru
}

\begin{abstract}
Нарождающаяся экономика знаний представляет собой новый этап в развитии Российской Федерации. Отличительной чертой этого периода является знание как производительная сила, которая выполняет четыре основные функции: воспроизводство, хранение, распространение и использование. Существенная дифференциация регионов России по уровню социально-экономического развития также оказывает существенное влияние на развертку экономики знаний в стране. Для оценки ее готовности предложено оперировать понятием «когнитивный потенциал региональной экономики», для которого в статье раскрыта система оценивающих показателей. Она включает в себя критерии в разбивке по функциям и показателям структуры, соотношения и среднедушевым величинам. Рассчитан когнитивный потенциал в динамике лет по всем регионам РФ. Дана характеристика регионов-лидеров, а также субъектов, существенно изменивших свое положение.
\end{abstract}

Ключевые слова: когнитивный потенциал; региональная экономика; рейтинговая оценка; экономика знаний; региональная статистика.

\section{Для цитирования:}

Цыренов Д. Д. Развитие методики оценки когнитивного потенциала региональной экономики // Вестник Бурятского государственного университета. Экономика и менеджмент. 2019. № 2. С. 82-90.

Экономика знаний, формируемая на современном этапе, предопределяет разработку системы объективных статистических показателей и индикаторов на макро-, мезо- и микроуровнях для ее целостного понимания [3; 6]. Система показателей и индикаторов экономики знаний на макро- и мезоуровне является более сложной [1; $10 ; 11]$. В основу заложены стандартные данные, которые применяются исследователями в области региональной экономики [7; 8]. Информационной базой исследования являются данные, отслеживаемые и регистрируемые органами государственной статистики ${ }^{1}$, а также некоторые информационные материалы, подготовленные Федеральной службой по интеллектуальной собственности².

В основу предлагаемой нами системы показателей и индикаторов положена классификация функций экономики знаний: воспроизводство, хранение, распространение и использование знаний (табл. 1). Основные процессы и явления, происходящие в экономике знаний, формируются в четырех указанных составляющих [9].

\footnotetext{
${ }^{1}$ URL: http://www.gks.ru

${ }^{2}$ URL: https://rupto.ru
} 
Д. Д. Цыренов. Развитие методики оценки когнитивного потенциала региональной экономики

Таблица 1

Система показателей когнитивного потенциала

\begin{tabular}{|c|c|c|c|c|}
\hline & $\begin{array}{c}\text { Производство } \\
\text { знаний }\end{array}$ & Распространение знаний & $\begin{array}{c}\text { Хранение } \\
\text { знаний }\end{array}$ & $\begin{array}{c}\text { Использование } \\
\text { знаний }\end{array}$ \\
\hline $\begin{array}{l}\text { Показатели } \\
\text { структуры }\end{array}$ & $\begin{array}{l}\text { Удельный вес } \\
\text { персонала, } \\
\text { занятого науч- } \\
\text { ными исследо- } \\
\text { ваниями и раз- } \\
\text { работками, в } \\
\text { структуре заня- } \\
\text { тых }\end{array}$ & $\begin{array}{l}\text { Удельный вес численно- } \\
\text { сти высококвалифициро- } \\
\text { ванных работников в об- } \\
\text { щей численности квали- } \\
\text { фицированных работни- } \\
\text { ков }\end{array}$ & $\begin{array}{l}\text { Удельный вес } \\
\text { организаций, } \\
\text { использовав- } \\
\text { ших серверы, в } \\
\text { общем числе } \\
\text { организаций }\end{array}$ & $\begin{array}{l}\text { Удельный вес } \\
\text { организаций, } \\
\text { осуществлявших } \\
\text { технологические, } \\
\text { организацион- } \\
\text { ные, маркетин- } \\
\text { говые иннова- } \\
\text { ции, } \\
\text { в общем числе } \\
\text { организаций }\end{array}$ \\
\hline $\begin{array}{l}\text { Показатели } \\
\text { соотноше- } \\
\text { ния }\end{array}$ & $\begin{array}{l}\text { Количество } \\
\text { поданных па- } \\
\text { тентных заявок } \\
\text { в расчете на } \\
1000 \text { работни- } \\
\text { ков, выпол- } \\
\text { нявших науч- } \\
\text { ные исследо- } \\
\text { вания и разра- } \\
\text { ботки }\end{array}$ & $\begin{array}{l}\text { Затраты на технологиче- } \\
\text { ские инновации в расчете } \\
\text { на одного занятого }\end{array}$ & $\begin{array}{lr}\text { Число персо- } \\
\text { нальных ком- } \\
\text { пьютеров } \\
\text { расчете на } 100 \\
\text { работников }\end{array}$ & $\begin{array}{l}\text { Объем иннова- } \\
\text { ционных това- } \\
\text { ров, работ, услуг } \\
\text { в расчете на од- } \\
\text { ного занятого }\end{array}$ \\
\hline $\begin{array}{l}\text { Показатели } \\
\text { на душу } \\
\text { населения }\end{array}$ & $\begin{array}{l}\text { Внутренние } \\
\text { затраты на } \\
\text { научные иссле- } \\
\text { дования и раз- } \\
\text { работки в рас- } \\
\text { чете на душу } \\
\text { населения }\end{array}$ & $\begin{array}{l}\text { Затраты на информаци- } \\
\text { онные и коммуникацион- } \\
\text { ные технологии в расчете } \\
\text { на душу населения }\end{array}$ & $\begin{array}{l}\text { Библиотечный } \\
\text { фонд в расчете } \\
\text { на душу насе- } \\
\text { ления }\end{array}$ & $\begin{array}{l}\text { Объем иннова- } \\
\text { ционных това- } \\
\text { ров, работ, услуг } \\
\text { в расчете на ду- } \\
\text { шу населения }\end{array}$ \\
\hline
\end{tabular}

Расчет интегрального показателя когнитивного потенциала региональной экономики осуществляется по четырем группам: производство знаний, распространение знаний, хранение знаний, использование знаний. Производство знаний осуществляется академической и вузовской наукой, распространение знаний закреплено за системой образования, хранением знаний занимается сеть библиотек и архивов, использование знаний осуществляется в реальном секторе экономики. Выделение указанных групп позволяет ранжировать регионы по совокупности стадий формирования и использования когнитивного потенциала. В рамках методики оценки когнитивного потенциала каждая его составляющая оценивается по трем показателям: показатели структуры, показатели соотношения и среднедушевые показатели.

Следующим этапом осуществляется «свертка» относительных показателей в итоговые оценки когнитивного потенциала, благодаря чему формируется рейтинг развития экономики знаний в регионах Российской Федерации.

В таблице 2 представлены значения когнитивного потенциала по субъектам РФ и места регионов по анализируемым годам (2013-2017 гг.) 
ВЕСТНИК БУРЯТСКОГО ГОСУДАРСТВЕННОГО УНИВЕРСИТЕТА.

Таблица 2

Значения когнитивного потенциала по субъектам РФ

\begin{tabular}{|c|c|c|c|c|c|c|}
\hline \multirow{2}{*}{ Регион } & \multicolumn{2}{|c|}{2013} & \multicolumn{2}{|c|}{2015} & \multicolumn{2}{|c|}{2017} \\
\hline & $\mathrm{K}$ & Место & $\mathrm{K}$ & Место & $\mathrm{K}$ & Место \\
\hline Белгородская область & 22,09 & 51 & 27,97 & 37 & 38,20 & 7 \\
\hline Брянская область & 19,38 & 73 & 26,11 & 49 & 24,90 & 51 \\
\hline Владимирская область & 23,87 & 39 & 29,70 & 29 & 29,35 & 30 \\
\hline Воронежская область & 25,56 & 27 & 29,56 & 30 & 28,64 & 37 \\
\hline Ивановская область & 24,62 & 33 & 29,50 & 31 & 30,41 & 28 \\
\hline Калужская область & 34,63 & 7 & 36,78 & 9 & 32,65 & 21 \\
\hline Костромская область & 24,40 & 36 & 33,23 & 13 & 30,17 & 29 \\
\hline Курская область & 25,60 & 26 & 27,28 & 43 & 28,95 & 35 \\
\hline Липецкая область & 28,54 & 14 & 35,03 & 11 & 36,85 & 10 \\
\hline Московская область & 36,95 & 5 & 41,95 & 6 & 42,93 & 5 \\
\hline Орловская область & 20,55 & 64 & 24,04 & 64 & 23,29 & 59 \\
\hline Рязанская область & 24,34 & 37 & 27,74 & 39 & 27,67 & 43 \\
\hline Смоленская область & 21,87 & 54 & 26,00 & 50 & 27,18 & 46 \\
\hline Тамбовская область & 22,17 & 48 & 25,38 & 55 & 28,05 & 41 \\
\hline Тверская область & 24,00 & 38 & 26,88 & 45 & 26,90 & 47 \\
\hline Тульская область & 24,71 & 32 & 31,16 & 25 & 34,15 & 18 \\
\hline Ярославская область & 28,45 & 15 & 31,95 & 19 & 33,10 & 20 \\
\hline г. Москва & 63,46 & 1 & 68,72 & 1 & 57,25 & 1 \\
\hline Республика Карелия & 20,21 & 68 & 26,85 & 46 & 23,98 & 56 \\
\hline Республика Коми & 21,75 & 55 & 26,37 & 47 & 24,27 & 55 \\
\hline Архангельская область & 24,50 & 35 & 25,64 & 51 & 36,20 & 12 \\
\hline Вологодская область & 22,15 & 50 & 34,53 & 12 & 26,37 & 48 \\
\hline Калининградская область & 19,66 & 72 & 24,02 & 65 & 23,31 & 58 \\
\hline Ленинградская область & 28,94 & 13 & 30,01 & 27 & 29,02 & 33 \\
\hline Мурманская область & 26,43 & 24 & 29,17 & 33 & 27,44 & 44 \\
\hline Новгородская область & 22,58 & 46 & 27,48 & 41 & 27,83 & 42 \\
\hline Псковская область & 21,71 & 56 & 25,56 & 54 & 24,48 & 54 \\
\hline г. Санкт-Петербург & 49,81 & 2 & 56,58 & 2 & 53,68 & 2 \\
\hline Республика Адыгея & 21,19 & 61 & 23,85 & 66 & 23,26 & 60 \\
\hline Республика Калмыкия & 23,17 & 45 & 27,52 & 40 & 23,96 & 57 \\
\hline Республика Крым & - & - & 25,61 & 52 & 21,51 & 70 \\
\hline Краснодарский край & 20,57 & 63 & 21,33 & 74 & 29,09 & 32 \\
\hline Астраханская область & 22,17 & 49 & 28,62 & 35 & 24,70 & 52 \\
\hline Волгоградская область & 21,35 & 58 & 23,29 & 67 & 22,04 & 69 \\
\hline Ростовская область & 23,39 & 43 & 29,12 & 34 & 28,25 & 40 \\
\hline г. Севастополь & - & - & - & - & 21,19 & 73 \\
\hline Республика Дагестан & 23,43 & 42 & 17,53 & 77 & 15,07 & 79 \\
\hline Республика Ингушетия & $\ldots$ & $78-80$ & 16,49 & 78 & 15,90 & 78 \\
\hline $\begin{array}{l}\text { Кабардино-Балкарская Рес- } \\
\text { публика }\end{array}$ & 19,94 & 71 & 21,18 & 75 & 19,26 & 77 \\
\hline $\begin{array}{l}\text { Карачаево-Черкесская Респуб- } \\
\text { лика }\end{array}$ & 18,62 & 75 & 20,89 & 76 & 20,70 & 75 \\
\hline $\begin{array}{l}\text { Республика Северная Осетия - } \\
\text { Алания }\end{array}$ & 20,68 & 62 & 22,36 & 71 & 22,21 & 68 \\
\hline Чеченская Республика & $\ldots$ & $78-80$ & 13,86 & 79 & 14,40 & 80 \\
\hline
\end{tabular}


Д. Д. Цыренов. Развитие методики оценки когнитивного потенциала региональной экономики

\begin{tabular}{|c|c|c|c|c|c|c|}
\hline Ставропольский край & 22,06 & 52 & 26,34 & 48 & 25,54 & 50 \\
\hline Республика Башкортостан & 25,38 & 30 & 29,92 & 28 & 30,88 & 26 \\
\hline Республика Марий Эл & 28,13 & 17 & 31,91 & 20 & 31,86 & 24 \\
\hline Республика Мордовия & 25,11 & 31 & 31,49 & 21 & 34,80 & 15 \\
\hline Республика Татарстан & 34,59 & 8 & 43,15 & 5 & 51,06 & 3 \\
\hline Удмуртская Республика & 20,03 & 70 & 24,46 & 61 & 27,26 & 45 \\
\hline Чувашская Республика & 23,21 & 44 & 33,13 & 14 & 33,47 & 19 \\
\hline Пермский край & 28,30 & 16 & 32,54 & 16 & 38,28 & 6 \\
\hline Кировская область & 23,45 & 41 & 27,25 & 44 & 28,67 & 36 \\
\hline Нижегородская область & 38,64 & 4 & 45,71 & 4 & 47,67 & 4 \\
\hline Оренбургская область & 24,53 & 34 & 25,08 & 57 & 25,92 & 49 \\
\hline Пензенская область & 26,27 & 25 & 31,30 & 23 & 32,38 & 23 \\
\hline Самарская область & 30,54 & 10 & 35,35 & 10 & 34,72 & 17 \\
\hline Саратовская область & 21,31 & 59 & 25,59 & 53 & 22,50 & 64 \\
\hline Ульяновская область & 25,43 & 29 & 28,58 & 36 & 28,99 & 34 \\
\hline Курганская область & 22,52 & 47 & 23,20 & 68 & 23,14 & 61 \\
\hline Свердловская область & 27,66 & 18 & 31,30 & 24 & 34,79 & 16 \\
\hline Тюменская область & 27,03 & 20 & 31,43 & 22 & 37,94 & 9 \\
\hline Челябинская область & 27,01 & 21 & 29,30 & 32 & 38,07 & 8 \\
\hline Республика Алтай & 26,49 & 23 & 25,23 & 56 & 24,56 & 53 \\
\hline Республика Бурятия & 20,27 & 67 & 22,83 & 70 & 20,87 & 74 \\
\hline Республика Тыва & 21,23 & 60 & 24,20 & 52 & 22,49 & 65 \\
\hline Республика Хакасия & 20,45 & 65 & 22,18 & 73 & 21,51 & 71 \\
\hline Алтайский край & 20,40 & 66 & 24,54 & 60 & 22,89 & 63 \\
\hline Забайкальский край & 16,73 & 76 & 23,11 & 69 & 19,40 & 76 \\
\hline Красноярский край & 29,72 & 11 & 32,28 & 17 & 30,46 & 27 \\
\hline Иркутская область & 22,00 & 53 & 24,92 & 59 & 22,29 & 67 \\
\hline Кемеровская область & 20,14 & 69 & 24,07 & 63 & 23,09 & 62 \\
\hline Новосибирская область & 27,43 & 19 & 30,36 & 26 & 29,25 & 31 \\
\hline Омская область & 23,86 & 40 & 27,31 & 42 & 28,44 & 38 \\
\hline Томская область & 32,39 & 9 & 37,97 & 8 & 35,58 & 14 \\
\hline Республика Саха (Якутия) & 25,52 & 28 & 27,76 & 38 & 28,38 & 39 \\
\hline Камчатский край & 29,37 & 12 & 32,65 & 15 & 31,69 & 25 \\
\hline Приморский край & 21,47 & 57 & 22,26 & 72 & 21,35 & 72 \\
\hline Хабаровский край & 26,51 & 22 & 32,04 & 18 & 36,47 & 11 \\
\hline Амурская область & 19,35 & 74 & 25,01 & 58 & 22,46 & 66 \\
\hline Магаданская область & 36,82 & 6 & 40,74 & 7 & 32,48 & 22 \\
\hline Сахалинская область & 45,46 & 3 & 49,78 & 3 & 35,73 & 13 \\
\hline Еврейская автономная область & 16,43 & 77 & $\ldots$ & $80-81$ & $\ldots$ & $81-82$ \\
\hline Чукотский автономный округ & $\ldots$ & $78-80$ & $\ldots$ & $80-81$ & $\ldots$ & $81-82$ \\
\hline
\end{tabular}

В таблице 3 представлены субъекты Федерации, занимающие ведущие позиции в представленном рейтинге. Рассмотрим опыт этих регионов по формированию и реализации когнитивного потенциала, который позволяет им удерживать передовые позиции в составленном рейтинге. 
Регионы, стабильно находящиеся в первой десятке регионов по величине когнитивного потенциала

\begin{tabular}{|l|c|c|c|}
\hline \multicolumn{1}{|c|}{ Наименование региона } & 2013 & 2015 & 2017 \\
\hline г. Москва & 1 & 1 & 1 \\
\hline г. Санкт-Петербург & 2 & 2 & 2 \\
\hline Нижегородская область & 4 & 4 & 4 \\
\hline Московская область & 5 & 6 & 5 \\
\hline Республика Татарстан & 8 & 5 & 3 \\
\hline
\end{tabular}

Москва как столица государства сосредоточила на своей территории фактически весь потенциал страны. Город удерживает за собой лидерство почти по всем исследуемым показателям когнитивного потенциала. Высокий потенциал Москвы подтверждается и международными рейтингами: город традиционно входит в лучшую сотню, по мнению Innovation Cities Index. Рынок интеллектуальных товаров и услуг в Москве растет более высокими по сравнению с общероссийскими темпами. Город сформировал более развитую инфраструктуру для интеллектуального бизнеса при активной поддержке со стороны Правительства Москвы. Благодаря приложенным усилиям Москва представляет собой место притяжения креативного класса населения и активно интегрируется в глобальную экономику.

Санкт-Петербург по достоинству несет звание наукограда, подтверждая его высокими результатами в научной и образовательной деятельности. Благодаря формированию продвинутого молодого поколения вместе с традиционно высокими культурными стандартами город формирует уникальную среду для реализации когнитивного потенциала. В Санкт-Петербурге функционирует значительное количество малых наукоемких предприятий, повышающих эффективность взаимодействия учреждений науки и субъектов малого предпринимательства. Санкт-Петербург является базой для проведения многих российских и международных мероприятий, что позволяет говорить о высоком значении города на «когнитивной» карте.

Нижегородская область - лидер Приволжского федерального округа. По многим разрабатываемым индексам и рейтингам регион уверенно входит в пятерку лучших по стране. Являясь промышленным регионом, Нижегородская область активно разрабатывает и внедряет в производство высокие технологии (удельный вес внедрения технологических инноваций - один из самых больших по стране). Субъект является сосредоточением учреждений высшего образования и академической науки. Продукция регионального производства активно поставляет за рубеж.

Для Московской области характерна самая высокая плотность наукоградов (8 из 13 по России). Высокие результаты реализации когнитивного потенциала достигаются за счет эффективной кластерной политики. Московская область особый упор делает на развитие и внедрение в широкое высокотехнологичное производство критических технологий. Регион активно привлекает иностранные инвестиции и успешно реализует интеллектуальную продукцию за рубежом.

Республика Татарстан находится в постоянном поиске новых прорывных направлений и механизмов и ежегодно вручает премию за 50 лучших идей. 
Д. Д. Цьренов. Развитие методики оценки когнитивного потенциала региональной экономики

Большие успехи связаны с созданной особой экономической зоной «Иннополис». В реальный сектор экономики активно внедряются региональные разработки в области развития критических технологий. Существенную роль играет развитая сеть учреждений высшего образования и Академии наук Татарстана.

В таблице 4 представлены субъекты Федерации, которые продемонстрировали за анализируемый период существенное улучшение своих позиций в составленном рейтинге.

Таблица 4

Регионы, значительно улучшившие свои позиции в рейтинге по величине когнитивного потенциала

\begin{tabular}{|l|c|c|c|}
\hline \multicolumn{1}{|c|}{ Наименование региона } & 2013 & 2015 & 2017 \\
\hline Белгородская область & 51 & 37 & 7 \\
\hline Тульская область & 32 & 25 & 18 \\
\hline Архангельская область & 35 & 51 & 12 \\
\hline Калининградская область & 72 & 65 & 58 \\
\hline Удмуртская Республика & 70 & 61 & 45 \\
\hline
\end{tabular}

Белгородская область на 5 анализируемых лет продемонстрировала стремительный рост по величине когнитивного потенциала. В основе этого - постоянный рост числа малых инновационных предприятий и участие их в реальном секторе экономики. Важным инструментом увеличения рейтинговой оценки является применение проектного подхода: регион сегодня - лидер по развитию проектного управления в России. Высоко зарекомендовал себя Фонд содействия развитию малых форм предприятий в научно-технической сфере.

Тульская область обеспечила себе перемещение вверх в рейтинге субъектов Федерации благодаря ряду факторов: создание особой экономической зоны промышленно-производственного типа «Узловая» и создание Фонда развития промышленности, которые с первых дней способствуют повышению когнитивного потенциала. Тульская область начинает работу по вовлечению региональных вузов в процессы коммерциализации научных исследований.

Архангельская область значительно улучшила свои позиции в рейтинге субъектов РФ благодаря созданному судостроительному инновационному территориальному кластеру. Другой фактор - вовлеченность региона в программы импортозамещения комплектующих для судостроительной отрасли в санкционных условиях. Также регион активно внедряет научные разработки благодаря федеральным программам освоения российской Арктики.

Калининградская область, несмотря на отмену режима особой экономической зоны, продемонстрировала за анализируемый период рост рейтинговых показателей. Будущие перспективы связаны с созданием сети бизнес-инкубаторов и дальнейшим развитием международного сотрудничества в научно-технической сфере.

Удмуртская Республика создала акционерное общество «Корпорация развития Удмуртской Республики», к функционалу которой отнесена организация эффективного взаимодействия между бизнесом, властью и объектами культуры и науки. Основной применяемый механизм - кластерная политика, в рамках ко- 
торой функционируют машиностроительный кластер и кластер производства нефтегазового оборудования.

В таблице 5 представлены субъекты Федерации, которые продемонстрировали за анализируемый период существенное ухудшение своих позиций в составленном рейтинге.

Таблица 5

Регионы, значительно ухудшившие свои позиции в рейтинге по величине когнитивного потенциала

\begin{tabular}{|l|c|c|c|}
\hline \multicolumn{1}{|c|}{ Наименование региона } & 2013 & 2015 & 2017 \\
\hline Сахалинская область & 3 & 3 & 13 \\
\hline Магаданская область & 6 & 7 & 22 \\
\hline Калужская область & 7 & 9 & 21 \\
\hline Ленинградская область & 13 & 27 & 33 \\
\hline Мурманская область & 24 & 33 & 44 \\
\hline
\end{tabular}

Незначительное снижение рейтинговой позиции лидера Сахалинской области связано с некоторыми проблемами в инвестиционной сфере в 2016 г., что было подтверждено в том числе и Агентством стратегических инициатив (падение на 20 позиций). Принятые после этого меры по созданию ряда технопарков, в том числе и детского «Кванториума», дают надежду на возвращение региона в десятку лучших по величине когнитивного потенциала.

Перемещение Магаданской области из первой десятки регионов в третью за анализируемый период объясняется ухудшением инвестиционного климата и показателей качества жизни, в основе чего лежит сокращение иностранных инвестиций и снижение прибыльности предприятий, в том числе функционирующих в научно-технической сфере.

Калужская область также переместилась на 15 позиций вниз в составленном рейтинге. Отдельные негативные стороны связаны с недостаточно активной патентной деятельностью учреждений науки и высшего образования, а также с некоторой неуравновешенностью в инновационной деятельности хозяйствующих субъектов с ее информационным обеспечением.

Ленинградская область за анализируемый период продемонстрировала падение на 20 пунктов. Ключевой причиной, по нашему мнению, является расформирование в 2014 г. Научно-технического совета при Губернаторе Ленинградской области. Другая проблема Ленинградской области связана с тем, что экономическая база региона сосредоточена в «неинновационных» секторах. Близость города федерального значения приводит к перетоку трудовых ресурсов и нехватке специалистов, способных повышать когнитивный потенциал региона.

Падение Мурманской области в представленном рейтинге на 20 позиций связано в первую очередь со свертыванием в 2010-2012 гг. работ по созданию передовых производственных технологий, замедлению темпов инвестиций в развитие производственного потенциала, что привело в конечном итоге к уменьшению объемов производства инновационных товаров.

В таблице 6 представлены данные о среднем уровне когнитивного потенциала по всем регионам Федерации за 2013, 2015 и 2017 гг. 
Д. Д. Цьренов. Развитие методики оценки когнитивного потенциала региональной экономики

Таблица 6

Рейтинговая динамика среднего уровня когнитивного потенциала

\begin{tabular}{|l|c|c|c|}
\hline \multirow{2}{*}{\multicolumn{1}{|c|}{ Параметр }} & \multicolumn{3}{c|}{ Рейтинговая оценка } \\
\cline { 2 - 4 } & 2013 & 2015 & 2017 \\
\hline производство знаний & 39,44 & 46,08 & 44,06 \\
\hline распространение знаний & 19,97 & 20,53 & 16,86 \\
\hline хранение знаний & 23,74 & 27,24 & 30,17 \\
\hline использование знаний & 18,34 & 25,24 & 24,60 \\
\hline интегральная оценка & 25,37 & 29,77 & 28,93 \\
\hline
\end{tabular}

В целом по стране когнитивный потенциал в части производства знаний демонстрирует небольшой рост. Связано это с улучшением условий для выработки нового знания - структурная реформа РАН и увеличение финансирования вузовской и академической науки. Постоянный рост демонстрирует сфера хранения знаний, что связано в первую очередь с цифровизацией библиотечной и архивной деятельности и последующим увеличением доступа к уже имеющимся знаниям. Незначительный рост характерен и для сферы использования знаний реальный сектор экономики начинает небольшими объемами внедрять результаты интеллектуальной деятельности. Существенная проблема видится в сфере распространения знаний - уменьшение бюджетного финансирования высшей школы с перераспределением в сторону среднего профессионального образования приводит к значительным проблемам в трансляции знания. Для выхода из сложившейся ситуации необходимо увеличить внимание федеральных органов власти к проблемам высшего образования в стране. Эффективным инструментом становится внедрение механизмов целеполагания и проектного менеджмента для ответа на вызовы цифровизации экономики $[2 ; 4 ; 5]$.

Можно отметить, что за 5 лет наблюдается незначительный рост в использовании когнитивного потенциала экономики. Необходимо отметить, что рейтинговые характеристики регионов по уровню развития экономики знаний построены на основе сравнительного анализа субъектов РФ между собой. Использование в качестве базы сравнения аналогичных показателей развитых стран существенно изменит рейтинговые позиции регионов.

\section{Литература}

1. Бадлуева М. П., Баженова В. С., Ванчикова Е. Н. О методике оценки творческого потенциала социально-экономической системы региона // Конкурентоспособность в глобальном мире: экономика, наука, технологии. 2017. № 4-3(39). С. 16-20.

2. Будаева И. О. Применение проектного менеджмента как наиболее эффективного инструмента управления интеллектуальным потенциалом в регионе // Вестник Забайкальского государственного университета. 2017. Т. 23, № 9. С. 134-143.

3. Будаева И. О., Эрдыниев Ж. Ч. Диалектика интеллектуального и институционального в структуре интеллектуального потенциала региона // Экономика и предпринимательство. 2017. № 8-1(85). С. 299-303.

4. Куликова Е. И. К вопросу развития систем целеполагания в управлении региональным рынком // Ученые записки Российской академии предпринимательства. 2016. № 46. C. $18-26$. 
5. Куликова Е. И. Цифровизация как основной тренд развития финансовых услуг // Финансовая жизнь. 2018. № 4. С. 67-70.

6. Мункуева И. С. Знание как наиболее производительный ресурс инновационной экономики // Вестник Бурятского государственного университета. 2014. № 2. С. 26-28.

7. Рубан В. А. Транспортный потенциал Байкальского региона // Российское предпринимательство. 2015. № 4(274). С. 593-600.

8. Рубан В. А., Метелева М. А. Проблемы социально-экономического развития регионов территориально-отраслевой системы проекта модернизации Байкало-Амурской магистрали // Транспортное дело России. 2017. № 3. С. 12-14.

9. Цыренов Д. Д. Систематизация общенаучных подходов к исследованию потенциала региональной экономики // European Social Science Journal. 2016. № 4. С. 178-186.

10. Цыренов Д. Д., Биликтуева Г. Д. Разработка статистической оценки когнитивной асимметрии регионов Сибирского федерального округа по уровню человеческого капитала // Омский научный вестник. 2014. № 3(129). С. 51-54.

11. Цыренов Д. Д., Слепнева Л. Р. Рейтинг регионов в зависимости от уровня развития экономики знаний // Известия Санкт-Петербургского государственного экономического университета. 2015. № 2 (92). С. 24-28.

\section{DEVELOPMENT OF METHODS FOR ASSESSING THE COGNITIVE POTENTIAL OF REGIONAL ECONOMY}

Dashi D. Tsyrenov

Cand. Sci. (Econ.),

Dorzhi Banzarov Buryat State University

24a Smolina St., Ulan-Ude 670000, Russia

E-mail: dashi555@mail.ru

The emerging knowledge economy is a new stage of the Russian Federation development The specific feature of this period is knowledge as a productive force, which performs four main functions: reproduction, storage, distribution and use. The significant differentiation of Russian regions in socio-economic development also has a significant impact on the formation of knowledge economy in the country. We have proposed to use the concept "cognitive potential of the regional economy", and revealed a system of evaluating indicators for it. This system includes criteria broken down by functions and indicators of structure, ratio, and per capita values. We have calculated the annualized cognitive potential of all Russian regions, characterized leading regions and the subjects of Federation that significantly changed their position.

Keywords: cognitive potential; regional economy; rating; knowledge economy, regional statistics. 